https://doi.org/10.15407/ujpe64.1.63

V.V. GOLOVANOVA, ${ }^{1}$ B.V. NAZARCHUK,${ }^{1}$ O.V. POSTNYI,${ }^{1}$ T.T. RANTALA,${ }^{2}$ N.V. TKACHENKO ${ }^{3}$ V.V. GOLOVANOV ${ }^{1}$

${ }^{1}$ Center for Innovation Technologies, South-Ukrainian National University (26, Staroportofrankovskaya Str., Odessa 65020, Ukraine; e-mail: sealolablue@yahoo.com)

2 Department of Physics, Tampere University of Technology

(P.O. Box 692, FI-33101, Tampere, Finland)

${ }^{3}$ Laboratory of Chemistry and Bioengineering, Tampere University of Technology (P.O. Box 541, FI-33101 Tampere, Finland)

\title{
PHOTOREACTIONS OF MACROCYCLIC DYES ON (1010) WURTZITE SURFACE - INTERPLAY BETWEEN CONFORMATION AND ELECTRONIC EFFECTS
}

\begin{abstract}
Macrocyclic dyes such as phthalocyanine and porphyrin molecules are modeled on (1010) wurzite surfaces using the DFT and molecular dynamics approaches. It is found that the single dye anchored on the wurtzite surface stabilizes in an inclined geometry with its core facing the surface at a tilting angle of $\mathrm{ca} 60^{\circ}$. The tilting of the dye relative to the crystal surface has a dual effect on the charge transfer from a chromophore to the semiconductor. Increasing the tilting angle leads to a stronger coupling between the lowest level of the semiconductor conduction band and dye's LUMO, thus raising the tunneling probability of the electron injection. By contrast, the electrostatic interaction between units upon the tilting of macrocycles results in a lowering of the molecule LUMO level with respect to the conduction band minimum of the wurzite crystal, which may hinder the electron transfer. The type of a linker and peripheral substituents significantly affect the mutual conformation of the moieties, and their proper choice can facilitate the photoinduced charge transfer reactions.

Ke ywords: macrocyclic dyes, wurzite, electron transfer, DFT.
\end{abstract}

\section{Introduction}

Semiconductor nanostructures hybridized with organic dyes attract significant interest due to their wide application range in solar energy conversion, photonics, sensors, and molecular electronics [13]. Among a relatively large choice of metal oxide templates for organic solar cells, $\mathrm{ZnO}$ being an inexpensive and environmentally friendly material with suitable band gap is considered as a promis-

(C) V.V. GOLOVANOVA, B.V. NAZARCHUK,

O.V. POSTNYI, T.T. RANTALA, N.V. TKACHENKO,

V.V. GOLOVANOV, 2019

ISSN 2071-0194. Ukr. J. Phys. 2019. Vol. 64, No. 1 ing replacement of $\mathrm{TiO}_{2}$. Furthermore, $\mathrm{ZnO}$ nanorods have advantages both for experimental studies and the computer modeling due to well-defined wurtzite single-crystalline surfaces often having lateral planes with the same crystallographic orientation (1010) [4]. CdSe quantum dots are another promising class of nanocomponents, which preserve the bulk-like hexagonal wurtzite crystal structure with the most abundant (1010) surface under ambient conditions $[5,6]$.

Ones of the most developed and studied hybrids based on these nanostructures are their conjugation with macrocyclic dyes such as porphyrin and phthalocyanine $(\mathrm{Pc})$ derivatives [7-9]. It should be 
noted, however, that hybrids with phthalocyanines are relatively unexplored due to the moderate energy conversion efficiencies achieved so far for Pcbased dye sensitized solar cells. Probably, the most common and well-known deactivation pathway is the aggregation of dyes, which may increase the nonradiative relaxation rate through intermolecular interactions or other processes sensitive to the aggregation. Reducing the aggregation is crucial for improving the solar cell performance. It has been previously reported that the aggregation can be reduced by adding bulky substituents around the macrocyclic dye core [10,11]. Employing the different peripheral substituents may also affect the tilt angles for the adsorbed moieties on the semiconductor surface.

Recent experimental publications provide support for the inclined geometry of macrocyclic dyes on the semiconductor surface. Direct transmission electron microscopy measurements of the porphyrin molecules anchored on $\mathrm{TiO}_{2}$ nanoparticles give evidence of their bending on the surface with an average tilt angle between the plane of the macrocycle and the $\mathrm{ZnO}$ surface normal of $53-60^{\circ}[12]$. The studies of the orientation for several macrocyclic dyes using X-ray reflectometry determine the binding angle in the range of 50-55 [13]. Ye et al. [14] employed surface sensitive vibrational spectroscopy to investigate the adsorption geometry of porphyrin derivatives on the $\mathrm{TiO}_{2}$ surface and have established a simple correlation between the geometry and the concentration of longlived electrons in the conduction band of $\mathrm{TiO}_{2}$. Based on the spectroscopy measurements, the tilting angle of the porphyrin molecules was estimated as 55$66^{\circ}$. Since the electron transfer reaction is to a great extent controlled by the conformations of the chromophores on the semiconductor surface plane, a detailed understanding of their orientation and molecular packing on the surface is critical for improving the charge transfer parameters.

An important tool for the analysis of such hybrid structures is the computational modeling. It can address many aspects of practical importance such as arrangements of molecular adsorbates on semiconductor surfaces and the mutual alignment of their energy levels [15-17]. Herein, we present the density functional theory and molecular dynamics computational modeling of phthalocyanine and porphyrin molecules equipped with different bulky peripheral groups and adsorbed on the most energetically favorable (1010) wurtzite surface which can be used to study both CdSe quantum dot-dye and $\mathrm{ZnO}$ nanorods-dye hybrids. Further to a theoretical investigation, we have compared our results with spectroscopic measurements of the differently prepared dyes and discussed the observed correlations.

\section{Models and Methods}

The hexagonal wurtzite structure of both $\mathrm{ZnO}$ and CdSe is the most common phase under ambient conditions. The structure consists of tetrahedrally coordinated metal cations and chalcogenide anions. The (1010) surface has been chosen as our model surface, since, according to numerous studies, it is the most energetically favorable and, therefore, the most abundant surface for both materials $[18,19]$. Furthermore, the $(10 \overline{1} 0)$ surface is nonpolar, thus allowing the identical terminations on the top and bottom surfaces of the slab. The (1010) surface slabs of 4,6 , and 8 layers were cut from the bulk structure with lateral lattice constants preliminarily optimized for a supercell built out of $2 \times 2 \times 2$ primitive cells of CdSe and $\mathrm{ZnO}$. The vacuum layer along the nonperiodic direction was $40 \AA$.

The six-layer slab has been chosen to study the surface-dye interaction. Due to the quantum confinement in the slab's perpendicular direction, our model is well reproducing the blueshift in energy typical of the CdSe quantum dots [20]. The dye molecules were anchored onto a surface via linkers of various lengths terminated by carboxylic groups attached onto two surface cations in a bidentate bridging mode, which ensures a strongest chemical bonding and is predominant according to previous reports [21]. The hydrogen atom released from the carboxylic acid group was bound to the surface anion atom near the attached moiety to preserve the charge neutrality of the system. The single dye was adsorbed per a surface area of $29 \times 31 \AA$, which corresponds to a surface coverage of $1 / 4$ of a monolayer. We chose this coverage to allow the dye to change its orientation and the tilt angle on the surface. Different supercells consisting of $6 \times 3 \times 6,6 \times 3 \times 9$, and $6 \times 3 \times 12$ unit cells were used to test the interaction between the neighboring dye molecules. The models were optimized by allowing both surfaces of the slab, dye, and linker, to relax.

We employ the ADF/BAND [22] software for DFT calculations. To describe the electron-electron exchange correlation, two different DFT functionals

ISSN 2071-0194. Ukr. J. Phys. 2019. Vol. 64, No. 1 


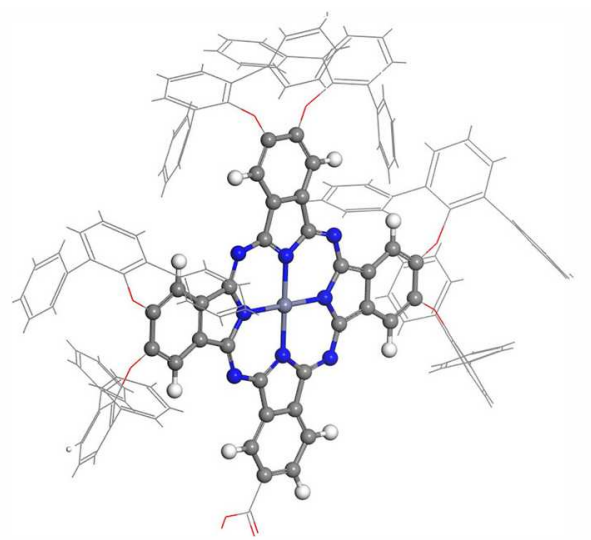

1

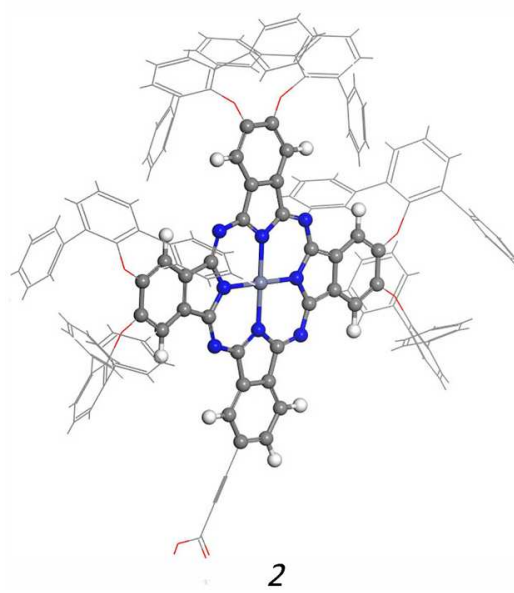

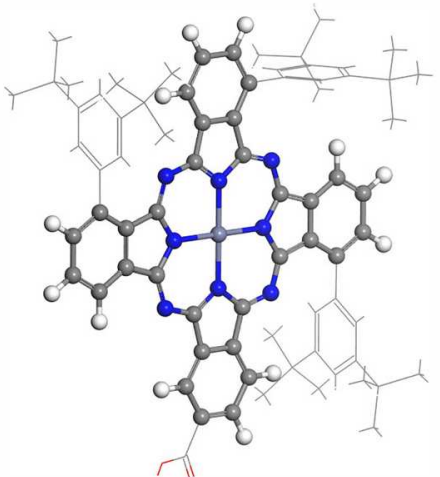

3

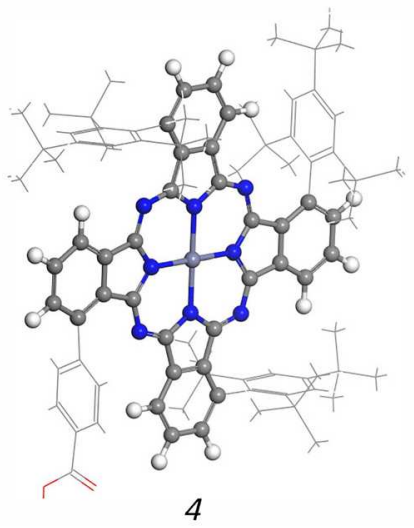

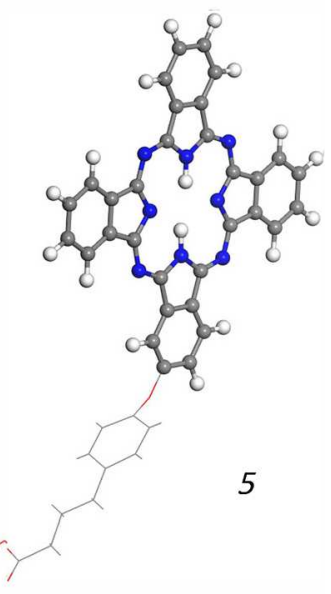

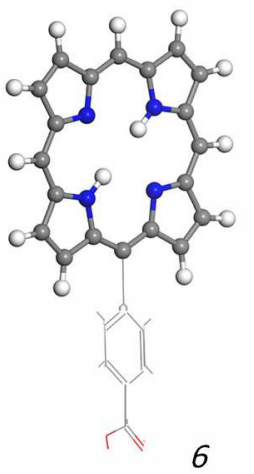

Fig. 1. Schemes of the macrocyclic dyes used in modeling. Zinc phthalocyanines with different peripheral groups and linker lengths (1-4); phthalocyanine molecule with a phenyl and carboxylic acid groups attached via an ether linkage (5); porphyrin molecule with a benzoic acid linker $(6)$

were used: generalized gradient approximation with PBEsol [23] and GLLB-SC [24]. The latter is based on the direct exchange potential approximation with the correlation potential from PBEsol and has been shown to yield good band gaps for bulk semiconductors [24]. The TZP basis set (a small frozen core) was chosen for all the types of atoms: H, C (1s), N (1s), O (1s), Se (3p), and Cd (3d). The empirical dispersion correction accounting for the van der Waals interactions between dye and the surface was included in the calculations using Grimme's DFT-D3 method [25].

In order to assess the morphology and conformations of the large chromophore molecules on the wurtzite surface under real conditions, we have carried out a canonical ensemble-molecular dynamics simulations at room temperature $(298 \mathrm{~K})$ in a con- stant volume (NVT-MD) using a Nose-Hoover thermostat, as implemented in the Forcite module of Materials Studio package [26]. The Dreiding force field [27] was used to evaluate the atomic forces, and the $100-$ ps trajectories for the studied systems were calculated with a 1-ps time step. The nonbonded electrostatic and van der Waals forces were controlled by the Ewald and atom-based summation methods with a cutoff distance of $9.5 \AA$.

\section{Results and Discussion}

\subsection{Coupling effects}

Chemical structures of porphyrin and phthalocyanine derivatives used in this study are shown in Fig. 1. The synthetic details of the compounds differing by the 
Table 1. Coupling strengths of porphyrin and a $\mathrm{ZnO}$ slab (eV) at different tilting angles

\begin{tabular}{|l|c|c|c|c|c|c|}
\hline \multirow{2}{*}{ Tilting angle, ${ }^{\circ}$} & 10 & 20 & 30 & 40 & 50 & 60 \\
\cline { 1 - 3 } Coupling strength, eV & 0.01 & 0.01 & 0.03 & 0.07 & 0.08 & 0.09 \\
\hline
\end{tabular}

bulky peripheral groups and the length of a linker together with the routine of their spectroscopic measurements were described elsewhere [7]. The role of the linker on the electron transfer occurring in hybrid systems has been the subject of intense investigations for the past few decades [28, 29]. In a simplified model, the charge transfer occurs through space, rather than through the bridge connecting the dye to the surface [14], and the corresponding electron tunneling mechanism is described by the exponential distance dependence. Besides the effect of solvent $[12,14]$, the linker to a great extend determines the distance between the dye and surface and their mutual orientation, which affects the electronic coupling between the two units. Accordingly, we have calculated porphyrin structures without peripheral substituents (compound 6 ) bound to the zinc oxide surface via the phenylbutyric acid spacer with angles ranging from $10^{\circ}$ to $70^{\circ}$. When porphyrin is tilted and twisted with its core facing the surface, the energies of its LUMO and HOMO decrease due to the attractive porphyrin-surface interactions until the energy minimum is reached at a tilting angle of $c a .60^{\circ}$. The latter value is in good agreement with the experimental estimations mentioned above. The main cause for a downshift of the frontier orbitals of porphyrin is the larger interaction of the $\pi$-orbital of dye's core with orbitals at the semiconductor surface. This conclusion is supported by the observed broadening ( $c a .0 .02 \mathrm{eV}$ ) of the frontier orbitals of a chromophore at the tilting.

In perturbation theory, the coupling between the orbitals results in the removal of a degeneracy at the crossing point of the corresponding levels. Accordingly, we estimated the coupling strength between the lowest level of the $\mathrm{ZnO}$ conduction band and the porphyrin LUMO level as the vertical distance between them at avoided crossing area. These data are taken from the DFT band structure calculations and listed in Tabl. 1 for different tilt angles. It was found that the coupling strength between the orbitals increases at the tilting of the dye.

\subsection{Effects of morphology}

Since the electron density of an excited molecular orbital is distributed over the conjugated $\pi$-system of a macrocycle, the distance from the ring edge to the semiconductor surface is one of the key parameters to compare the rates of photoinduced electron transfer for different dyes. Due to the expected exponential distance dependence of the electron transfer dynamics, even a modest change of the angle (and thus, the distance) may have a substantial impact on the transfer rate. Furthermore, equipping a molecule with bulky peripheral groups may affect the tilting angle due to steric restrictions. We chose compounds 1-4 from Fig. 1 to investigate the role of the linker length and different peripheral groups. The electron injection time constants measured by the transient absorption spectroscopy and the corresponding distances between the $\mathrm{ZnO}(10 \overline{1} 0)$ surface plane and the nearest edge of the macrocycle core calculated by DFT for relaxed arrangements of the dye molecules on the semiconductor surface are listed in Tabl. 2. Results of DFT modeling are in good agreement with the ones obtained by molecular dynamics simulations performed in the previous study [7]. Out of the four phthalocyanines presented in Tabl. 2, the slowest electron injection is observed for compounds 1 and 2 that have the most bulky peripheral groups. These two phthalocyanines are the most restricted when approaching the $\mathrm{ZnO}$ surface. The specific structure of 3 and 4 allows their macrocycle cores to appear closer to the surface. Since modeled molecules with shortest edgeto-surface distances exhibit the fastest electron injection times observed experimentally, we can deduce that the electron transfer reactions are largely controlled by the distance between the dye and the semiconductor surface plane. As noted previously [7], the electron injection time does not correlate with the length of the linker connecting the $\mathrm{Pc}$ to $\mathrm{ZnO}$. Indeed, the electron injection time constants for 1 and 2 are practically the same, even though 2 has a longer linker, and one would expect a longer distance be- 
Table 2. Time constants for the electron injection and electron transfer (ps), distance between the $\mathrm{ZnO}(10 \overline{1} 0)$ surface plane and the macrocycle edge $(\AA)$ in tilted alignments of the dye after the relaxation for different compounds, their tilting angles $\left({ }^{\circ}\right)$, and characteristic MD motion times (ps)

\begin{tabular}{|c|c|c|c|c|c|}
\hline \multirow{2}{*}{ Compound } & $\begin{array}{c}\text { Electron } \\
\text { injection, } \tau_{\text {in }}, \mathrm{ps}\end{array}$ & $\begin{array}{c}\text { Electron } \\
\text { transfer, } \tau_{\mathrm{ET}}, \mathrm{ps}\end{array}$ & $\begin{array}{c}\text { Distance, } \\
\AA\end{array}$ & $\begin{array}{c}\text { Tilting } \\
\text { angle, }\end{array}$ & $\begin{array}{c}\text { MD characteristic } \\
\text { motion time, } \tau_{\text {rel }}, \text { ps }\end{array}$ \\
\hline 1 & $5.0 \pm 0.6$ & $85 \pm 27$ & 3.05 & 62.9 & 31.6 \\
3 & $5.7 \pm 0.7$ & $125 \pm 20$ & 3.61 & 45.0 & 85 \\
4 & $0.7 \pm 0.2$ & $82 \pm 5$ & 2.85 & 5.6 \\
\hline
\end{tabular}

tween the Pc core and the $\mathrm{ZnO}$ surface, leading to a slower injection. Modeling provides insight on the observed discrepancy indicating that a longer linker ensures a high flexibility for the anchored molecule. In particular, compound 2 with a longer linker strongly tilts toward the surface. Thus, the difference in the edge-to-surface distances for compounds 1 and 2 is vanishing that eventually results in comparable injection time constants for these two Pcs.

\subsection{Aggregation effects}

One of the goals in sensitizing semiconductors with organic dye molecules is to make the dye monolayer as dense as possible. Unfortunately, the higher the monolayer density, the higher the aggregation of dyes, which introduces alternative channels for the relaxation of excited states and reduces the efficiency of the electron injection. A common practice to minimize the undesirable effects caused by aggregation is to equip the molecule with bulky peripheral groups that do not allow two dye molecules to stack together, but have no effect on the photophysical properties of the chromophores. Figure 2 illustrates relaxed geometries of the unmodified Pc molecule (compound 5) and Pcs decorated with various aggregation-reducing groups (compounds 3 and 4 ) at different surface coverages. The lonely stayed unmodified molecules tend to tilt on the surface. While, in a dense monolayer, they form a serpentine-like structure, pointing out on the strong intermolecular interactions between the aggregated phthalocyanines. An important outcome of the modeling is that the closely packed bulky dyes stay more upright at the separation length comparable with their spread size due to the interaction between the extended peripheral groups of the neighboring Pcs. Out of compounds 1-4, compound 3 is the least protected from intermolecular interactions and, therefore, is the most aggregated one. This is corroborated by the time resolved spectroscopy measurements [7], which exhibit the appearance of a sharp transient absorption band at $995 \mathrm{~nm}$ for $\mathrm{ZnO}$ samples modified with compound 3. This band corresponds to the Pc anion and is not observed for other samples. The most reasonable cause for the anion formation is the intermolecular charge separation in the Pc aggregates. This process can compete with the electron injection into $\mathrm{ZnO}$ and may reduce the efficiency of the system.

It is worth noticing that the characteristic time of the $\mathrm{Pc}$ motion on the $\mathrm{ZnO}$ surface estimated by molecular modeling is in the range $50-100 \mathrm{ps}, \tau_{\text {rel }}$ in Tabl. 2. In the samples additionally covered by SpiroOMeTAD, a hole-transporting material, the primary charge separation is shifted to Pc | Spiro-OMeTAD interface generating a $\mathrm{Pc}$ anion. Then the anion injects an electron to $\mathrm{ZnO}$ with the time constant listed in Tabl. 2 as $\tau_{\mathrm{ET}}$. The values of $\tau_{\text {rel }}$ and $\tau_{\mathrm{ET}}$ are close to each other, indicating that the molecular motion can be in control over the electron transfer at few tens of ps or longer time. However, this motion does not affect the electron injection of the excited Pc, which is much faster $(<15 \mathrm{ps})$.

\subsection{Electronic effects}

Though the simplified model considering the distance between the moieties as a key factor, which determines the electron transfer reaction, is applicable in many cases, the charge transfer in hybrids is a complex process controlled by the interplay between conformation and electron-induced effects at the interface. We studied this effect on the Pc molecule without peripheral substituents, e.g., compound 5 .

In particular, we found that the tilting of a $\mathrm{Pc}$ molecule toward the surface leads to a lowering of its 


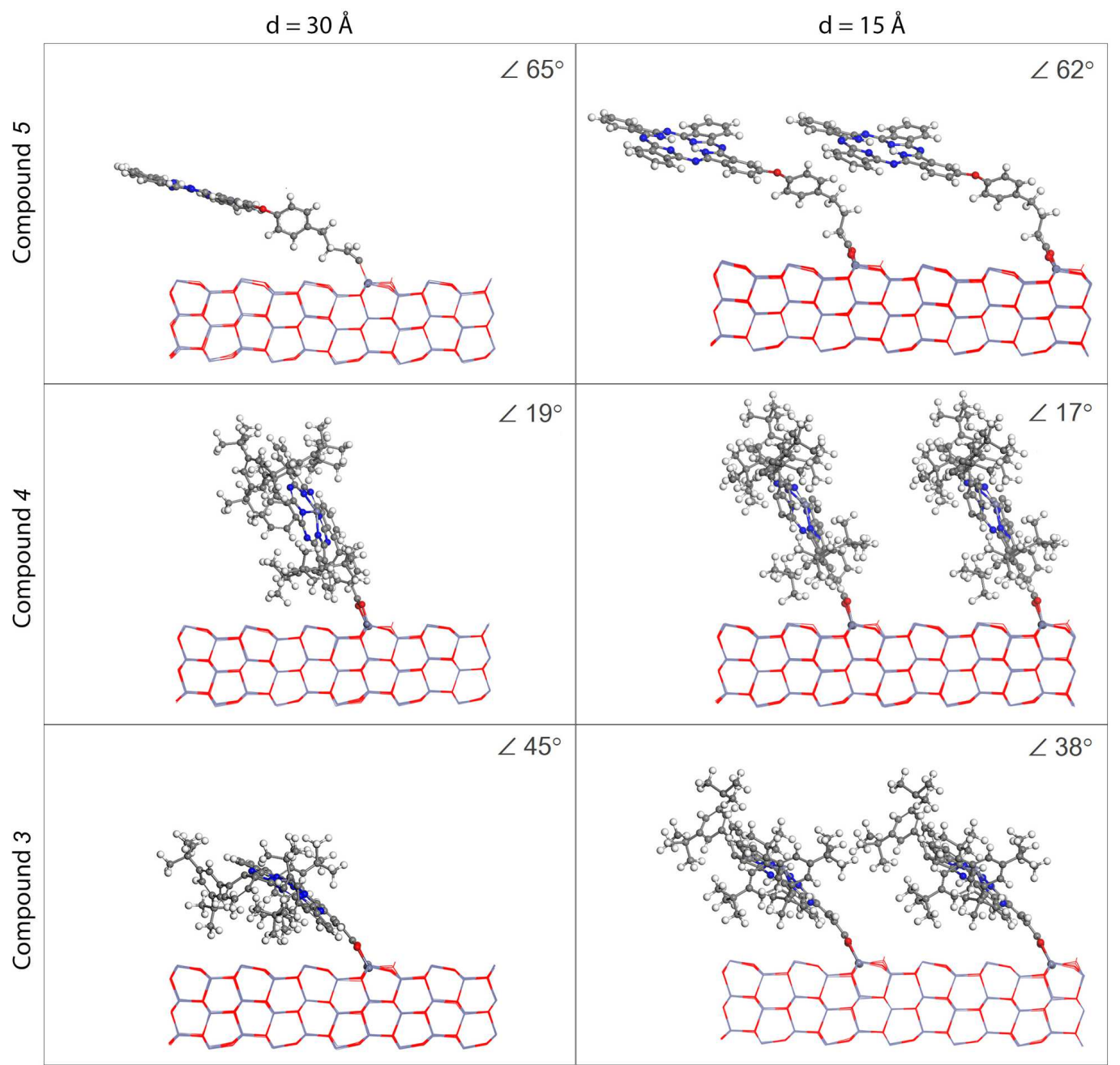

Fig. 2. Effect of the surface density of phthapocyanine molecules unmodified (compound 5) and modified with bulky peripheral groups (compounds 4 and 3) on their tilting angle on the $\mathrm{ZnO}$ (1010) surface. Distance between the centers of macrocycle cores is denoted as $d$

frontier orbitals relative to the lowest level of the conduction band of the semiconductor, see Fig. 3. Calculations of the tilted molecule using the GLLB-SC functional resulted in a configuration, where the energy level of the dye's LUMO becomes lower than the conduction band minimum of the CdSe slab. Thus, in spite of shortening the distance between the substrate and the sensitizing dye, the tilting of the molecule may inhibit an electron transfer reaction in the system. The obtained results are consistent with the recently reported lack of electron transfer from the LUMO of Pc to CdSe quantum dots [20]. Another factor that makes charge transfer from a macrocy- cle to the semiconductor surface unfavorable is increasing the number of peripheral groups around the dye, which leads to a lowering in the energy of the HOMO/LUMO system of a chromophore. Earlier, we have found that the saturation of $\mathrm{Pc}$ with eight phenylbutyric acid linkers attached to the macrocycle via an oxygen atom (as in compound 5, Fig. 1) causes a significant downward shift $(0.1-0.3 \mathrm{eV})$ in frontier orbital energies [8]. The linker can also play a substantial role in electron transfer by providing the through-bond electron tunneling mediated by a bridge. In the latter case, the presence of electronic states in a linker close in energy to those involved in 

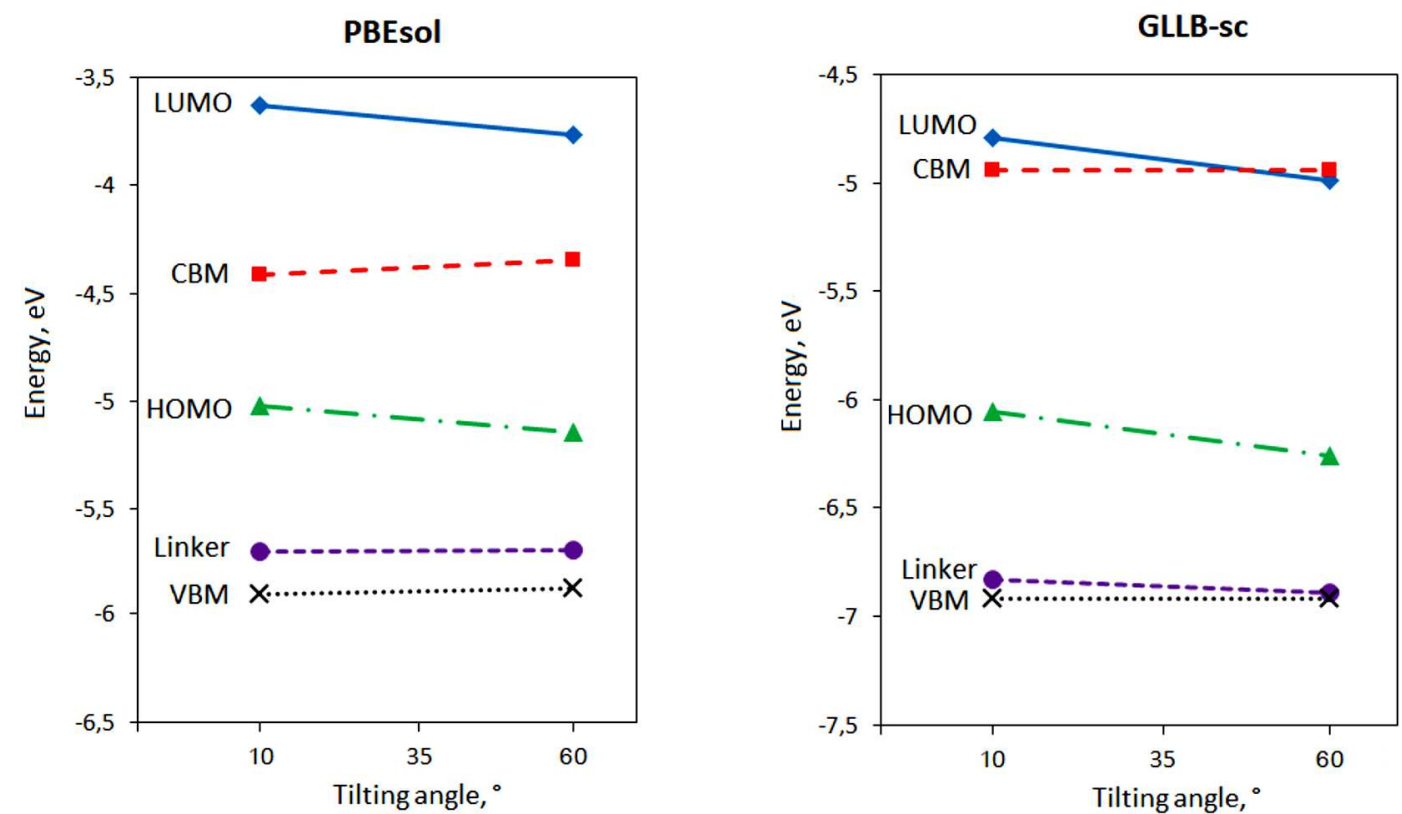

Fig. 3. Shifting the bands of a CdSe slab and an anchored phthalocyanine molecule at the tilting of the dye with respect to the surface. HOMO and LUMO correspond to the phthalocyanine highest occupied and lowest unoccupied orbitals, VBM and CBM - valence band maximum and conduction band minimum of the CdSe slab, and Linker reflects the energy position of the phenyl group orbital of the bridge

the electron transfer reaction may strongly alter the rate of charge transfer, also in cases where the electron is never localized in the bridge. Accordingly, we have found that the occupied energy state associated with the phenyl group of the linker is located between the valence band maximum of CdSe and the HOMO of Pc (Fig. 3), which ensures a suitable wiring pathway or virtual states for the hole transfer from cadmium selenide to Pc in their hybrid structures. The enhanced bridge conjugation serves as a better holetunneling channel, by pointing to the possible electron donor behavior of a phthalocyanine molecule in its hybrids with CdSe nanostructures.

\section{Conclusions}

The single macrocyclic dye anchored on the wurtzite surface via a phenylbutyric linker stabilizes in inclined geometry with its core facing the surface at a tilting angle of $c a .60^{\circ}$, while the closely packed bulky dyes stay in a more upright position due to the interaction with their neighbors. The proper choice of the peripheral substituents strongly affects the structure of the organic layer and opens opportunities for both reducing the aggregation of chromophores and the facilitation of the electron transfer reaction.
The tilting of dyes has a dual effect on the photoinduced charge transfer as a result of the interplay between the conformational and electronic effects. Obviously, shortening the distance between moieties enhances the tunneling probability for the electrons. On the other hand, the unfavorable relative position of the bands induced by a strengthening of the electronic interactions at the tilting may inhibit the electron transfer reaction between the dyes and the surface. Furthermore, we have found that a phenylbutyric linker may also have a twofold effect on the charge transfer by mediating the mutual conformation of the moieties and providing a suitable intermediate state for the hole transfer from the valence band of the semiconductor to a dye.

This work was supported by NATO SPS MYP project NANEOS, Grant No.985043. Computational resources were provided by the CSC-IT Center for Science, Espoo, Finland.

1. P. Docampo, S. Guldin, T. Leijtens, N. Noel, U. Steiner, H. Snaith. Lessons learned: From dye-sensitized solar cells to all-solid-state hybrid devices. Adv. Mat. 26, 4013 (2014). 
2. N. Kaura, M. Singh, D. Pathak, T. Wagner, J. Nunzid. Organic materials for photovoltaic applications: Review and mechanism. Synthetic Metals 190, 20 (2014).

3. V. Golovanov, V. Smyntyna, G. Mattogno, S. Kasiulis, V. Lantto. Oxygen interaction of CdS-based gas sensors with different stoichiometric composition. Sensors and Actuators B 26-27, 108 (1995).

4. S. Dag, S. Wang, L. Wang. Large surface dipole moments in ZnO nanorods. Nano Letters 11, 2348 (2011).

5. S. V. Kilina, D.S. Kilin, O.V. Prezhdo. Breaking the phonon bottleneck in PbSe and CdSe quantum dots: Timedomain density functional theory of charge carrier relaxation. ACS Nano 3 (1), 93 (2009).

6. J.M. Azpiroz, F. De Angelis. Ligand induced spectral changes in CdSe quantum dots. ACS Appl. Mater. Interfaces 7 (35), 19736 (2015).

7. K. Virkki, H. Hakola, M. Urbani, L. Tejerina, M. Ince, M. Diaz, T. Torres, V. Golovanova, V. Golovanov, N. Tkachenko. Photoinduced electron injection from zinc phthalocyanines into zinc oxide nanorods - Aggregation effects. J. Phys. Chem. C 121 (17), 9594 (2017).

8. V.V. Golovanov, B.V. Nazarchuk, V.V. Golovanova, N.V. Tkachenko, T.T. Rantala. Effects of orientation at the phthalocyanine-CdSe interface on the electron transfer characteristics. Phys. Chem. Chem. Phys. 19, 10511 (2017).

9. M. Niskanen, M. Kuisma, O. Cramariuc, V. Golovanov, T. Hukka, N. Tkachenko, T.T. Rantala. Porphyrin adsorbed on the (1010) surface of the wurtzite structure of $\mathrm{ZnO}$ - conformation induced effects on the electron transfer characteristics. Phys. Chem. Chem. Phys. 15 (40), 17408 (2013).

10. H. Matsuzaki, T. Murakami, N. Masaki, A. Furube, M. Kimura, S. Mori. Dye aggregation effect on interfacial electron-transfer dynamics in zinc phthalocyaninesensitized solar cells. J. Phys. Chem. C 118, 17205 (2014).

11. L. Tejerina, M. Martinez-Diaz, M. Nazeeruddin, T. Torres. The influence of substituent orientation on the photovoltaic performance of phthalocyanine-sensitized solar cells. Chem. - Eur. J. 22, 4369 (2016).

12. H. Imahori, S. Kang, H. Hayashi, M. Haruta, H. Kurata, S. Isoda, S. Canton, Y. Infahsaeng, A. Kathiravan, T. Pascher, P. Chabera, A. Yartsev, V. Sundstrom. Photoinduced charge carrier dynamics of $\mathrm{Zn}$-porphyrin- $\mathrm{TiO}_{2}$ electrodes: The key role of charge recombination for solar cell performance. J. Phys. Chem. A 115, 3679 (2011).

13. M. Griffith, M. James, G. Triani, P. Wagner, G. Wallace, D. Officer. Determining the orientation and molecular packing of organic dyes on a $\mathrm{TiO}_{2}$ surface using X-ray reflectometry. Langmuir 27, 12944 (2011).

14. S. Ye, A. Kathiravan, H. Hayashi, Y. Tong, Y. Infahsaeng, P. Chabera, T. Pascher, A. Yartsev, S. Isoda, H. Imahori, V. Sundström. Role of adsorption structures of $\mathrm{Zn}$-porphyrin on $\mathrm{TiO}_{2}$ in dye-sensitized solar cells stud- ied by sum frequency generation vibrational spectroscopy and ultrafast spectroscopy. J. Phys. Chem. C 117, 6066 (2013).

15. V. Golovanov, V. Golovanova, T.T. Rantala. Thermal desorption of molecular oxygen from $\mathrm{SnO}_{2}$ (110) surface: Insights from first-principles calculations. J. Chem. Phys. Solids 89, 15 (2016).

16. V. Golovanov, T. Kortelainen, T.T. Rantala. Stability of siloxane couplers on pure and fluorine doped $\mathrm{SnO}_{2}(110)$ surface: a first principles study. Surf. Sci. 604 (19-20), $1784(2010)$.

17. N. Ozcan, T. Kortelainen, V. Golovanov, T.T. Rantala, J. Vaara. Electron spin resonance parameters of bulk oxygen vacancy in semiconducting tin dioxide. Phys. Rev. B 81 (23), 235202 (1-10) (2010).

18. Y. Siao, P. Liu, Y. Wu. Ab initio study of atomic hydrogen on ZnO surfaces. Appl. Phys. Expr. 4, 125601 (2011).

19. V. Smyntyna, V. Golovanov, S. Kasiulis, G. Mattogno, G. Righini. Influence of chemical composition on sensitivity and signal reproducibility of CdS sensors of oxygen. Sensors and Actuators B 24-25, 628 (1995).

20. M. Arvani, K. Virkki, F. Abou-Chahine, A. Efimov, N.V. Tkachenko, D. Lupo. Photoinduced hole transfer in QD-phthalocyanine hybrids. Phys. Chem. Chem. Phys. 18, 27414 (2016).

21. N. Moreira, A. da Rosa, T. Frauenheim. Covalent functionalization of $\mathrm{ZnO}$ surfaces: a density functional tight binding study. Appl. Phys. Lett. 94, 193109 (2009).

22. BAND2014, SCM, Theoretical Chemistry, Vrije Universiteit, Amsterdam, The Netherlands, http://www.scm.com.

23. J. Perdew, A. Ruzsinszky, G. Csonka, O. Vydrov, G. Scuseria, L. Constantin, X. Zhou, K. Burke. Restoring the density-gradient expansion for exchange in solids and surfaces. Phys. Rev. Lett. 102, 039902 (2009).

24. M. Kuisma, J. Ojanen, J. Enkovaara, T.T. Rantala. KohnSham potential with discontinuity for band gap materials. Phys. Rev. B 82, 115106 (2010).

25. S. Grimme, J. Antony, S. Ehrlich, H. Krieg. A consistent and accurate $a b$ initio parametrization of density functional dispersion correction (DFT-D) for the 94 elements H-Pu. J. Chem. Phys. 132, 154104 (2010).

26. O. Ermer. Bonding Forces (Springer, 1976).

27. S. Mayo, B. Olafson, W. Goddard. Dreiding: A generic forcefield. J. Phys. Chem. 94, 8897 (1990).

28. J. Sukegawa, C. Schubert, X. Zhu, H. Tsuji, D. Guldi, E. Nakamura. Electron transfer through rigid organic molecular wires enhanced by electronic and electron-vibration coupling. Nature Chem. 6, 889 (2014).

29. B. Pelado, F. Abou-Chahine, J. Calbo, R. Caballero, P. Cruz, J. Junquera-Hernandez, E. Orti, N. Tkachenko, F. Langa. Role of the bridge in photoinduced electron transfer in porphyrin-fullerene dyads. Chem. Eur. J. 21, 1 (2015).

Received 20.04.18 
В.В. Голованова, Б.В. Назарчук, О.В. Постний, Т.Т. Рантала, М.В. Ткаченко, В.В. Голованов

\section{ФОТОРЕАКЦІЇ МАКРОЦИКЛІЧНИХ}

СПОЛУК НА ПОВЕРХНІ ВЮРЦИТУ (101̄0) ВЗАЄМОВПЛИВ КОНФОРМАЦІЇ

\section{ТА ЕЛЕКТРОННИХ ЕФЕКТІВ}

$\mathrm{P}$ е $з$ ю м е

Макроциклічні сполуки, такі як фталоціанін та порфірин було змодельовано за допомогою методів функціонала електронної густини та молекулярної динаміки на поверхні

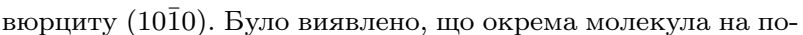
верхні вюрциту стабілізується у нахиленому стані під кутом $60^{\circ}$ між її кільцем та поверхнею. Нахил молекули відносно поверхні кристала двояко впливає на перенос заряду з хромофора до напівпровідника. Збільшення кута нахилу призводить до більш сильної взаємодії між нижчим рівнем зони провідності напівпровідника та LUMO молекули, таким чином підвищуючи ймовірність тунелювання електрона та його інжекції. 3 іншого боку, при нахилі макроциклу зростає електростатична взаємодія між молекулою та поверхнею кристала, що призводить до зниження LUMO молекули по відношенню до мінімуму зони провідності вюрциту, що, в свою чергу, може перешкоджати переносу електрона. Тип лінкера та периферійні групи можуть значно впливати на взаємне розташування фрагментів системи, та їх правильний вибір може сприяти фотоіндукованим реакціям переносу заряду. 